\title{
Considering the information technology for structural health monitoring (SHM) systems
}

\author{
Mikhail Emelianov ${ }^{*}$ \\ Moscow State University of Civil Engineering, Yaroslavskoe shosse, 26, Moscow, 129337, Russia
}

\begin{abstract}
The purpose of the research is to develop information technology for designing systems for monitoring load-bearing structures elements of buildings and structures of a high responsibility category based on the information about on the construction site and engineering survey results to obtain the automatic mode of results required for the development of these systems. The article describes the procedure for developing structural health monitoring (SHM) projects for the building and structures, based on the specific features of the development control and measuring system for building and structures and the engineering experience of designing these systems. The article presents the algorithms and macros that form the basis of the developed information technology, recommendations for determining the control parameters, the composition of the measuring equipment. The fundamentals of information technology development outlined in the article allow the development of algorithms and programs for the automated analysis of information about the construction and the construction site. The result of the analysis is the data necessary for the development of monitoring systems for buildings and structures of a higher category of responsibility.
\end{abstract}

\section{Introduction}

Currently in Russia, the number of complex construction of unique, high-rise, and longspan constructions is growing. Preventing accidents at these constructions is an important government task.

According to the results of the analysis of world experience it follows that at present the control of load-bearing structures is most efficiently performed using a system for monitoring the technical condition of objects, including automatic monitoring systems operating in continuous mode.

According to the Russian Federation document [1] system health monitoring (hereinafter - SHM) must be installed on threatening objects, objects of complex design, unique objects.

The development of automatic monitoring systems was researched in numerous works of Russian and foreign researchers [2-22]. An analysis of engineering practice shows that at present, automation systems for developing projects of SHM in the Russian Federation do not currently exist.

\footnotetext{
${ }^{*}$ Corresponding author: emelianov@mgsu.ru
} 
Automating of the SHM design for buildings and structures of a high responsibility category based on the data on the construction site and the results of engineering surveys will reduce the time needed to develop the system by optimizing the design process.

To automate the development of SHM projects, it is necessary to develop an information technology for data collection and analysis about the construction object and engineering survey results, allowing the user to receive recommendations on the monitoring mode, the composition of the measuring equipment and its installation sites.

\section{Research method}

Based on the world experience in the development of SHM and automation methods [23] it was found that the most effective way to automate the development of SHM is to develop software blocks for data collection and analysis that function in the following main stages of SHM realization works:

- data collection for the design features of the object and features of the construction site

- determination of the monitoring mode;

- determination of the threat model: the model of construction objects' transition to a partially operable or emergency state due to the development of natural and manmade processes leading to a dangerous changes in the stress-strain state of the structures and soils;

- formation of a list for the vital structures that must be controlled using the monitoring procedure;

- determination of the parameters that must controlled using the monitoring system and value ranges that correspond different operating conditions.

- determination of the optimal measuring equipment composition and its installation sites location,

and allowing the user to receive recommendations on the monitoring mode, the main threat models, the measuring equipment composition and location based on the information about the object and the results of engineering surveys.

The logical work sequence of the blocks is integrated into the information technology of the development of monitoring systems for buildings and structures.

Development of information technology requires the following tasks:

- development of a questionnaires for the collection and subsequent analysis of baseline data about structure and the results of engineering surveys;

- development of the data analysis block for constructions and an engineering surveys.

- database formation for:

$$
\begin{aligned}
& \circ \text { monitoring modes; } \\
& \circ \text { threat models; } \\
& \circ \text { measuring equipment. }
\end{aligned}
$$

- development of a form for presenting results.

The collection of data about the construction and construction site should be carried out electronically in the form of questionnaires. At the same time, the amount of data should be sufficient for the preparation of expert assessment of:

- a purpose and design features of the construction ;

- features of the construction site.

To determine the automatic monitoring mode, an algorithm for analyzing information about the construction and the guidelines of the current regulatory documents (Fig. 1) was 
developed. The realization result of said algorithm is the logical conclusion considering the monitoring mode with the reference to the regulation documentation.

The main threat models for buildings and structures should be determined based on the analysis of a group of typical objects, considering:

- constructive and architectural features of objects;

- causes of accidents of similar construction objects;

- analysis of engineering surveys and project documentation;

- modeling results (mathematical or physical) of the load-bearing structures under operational load;

- $\quad$ prediction of dangerous natural and man-made phenomena and processes.

To determine the list of the most loaded structural elements to be controlled, a software macro was developed in the environment of finite element modeling, the algorithm of which is shown in Fig. 2

The result of the macro is a location, stresses and displacement values of the nodes and elements of the model, the values constitute a fixed percentage of the allowed maximum values.

The use of this macro allows in the automatic mode to determine the most loaded areas of structural elements, which is necessary to determine the control parameters, requirements for the measuring devices accuracy.

The main parameters of the control of buildings and structures should be determined depending on the analysis of threat models and factors that have a significant impact on the supporting structures using finite elements model (hereinafter - FEM).

The main criteria for the selection of control devices for inclusion in the monitoring system of supporting structures is the compliance of the measuring instruments with the following requirements:

- reliability of measurements;

- obtaining the actual values of the measured values with a given accuracy at minimum time and material costs;

- the possibility of collecting, combining and processing information obtained from various measuring instruments in the composition of the monitoring system.

Based on the analysis of various monitoring technologies and engineering experience in the development of SHM projects, it was determined that in order to obtain the most complete picture of the behavior of the load-bearing structures of a building under load, the complex application of the following types of control is necessary:

- geodetic control methods to determine the change in the position of the object;

- $\quad$ stress-strain state of the foundation and the above-ground parts;

- $\quad$ ground base control;

- the control of dynamic parameters (natural frequencies and modes of oscillation) of the structure.

The composition of measuring equipment for SHM should be presented in the form of two lists determined on the basis of the analysis:

a) basic threat models;

b) features of the object and the construction site.

At the same time, the list of measuring equipment for monitoring of the parameters defined using the key threat models will be the same for all objects of this type (for example, high-rise buildings). The composition of the measuring equipment for monitoring of the parameters is determined using the information about the structures and the construction site will be determined by the design features of the specific construction object and the results of engineering surveys carried out at the construction site. 


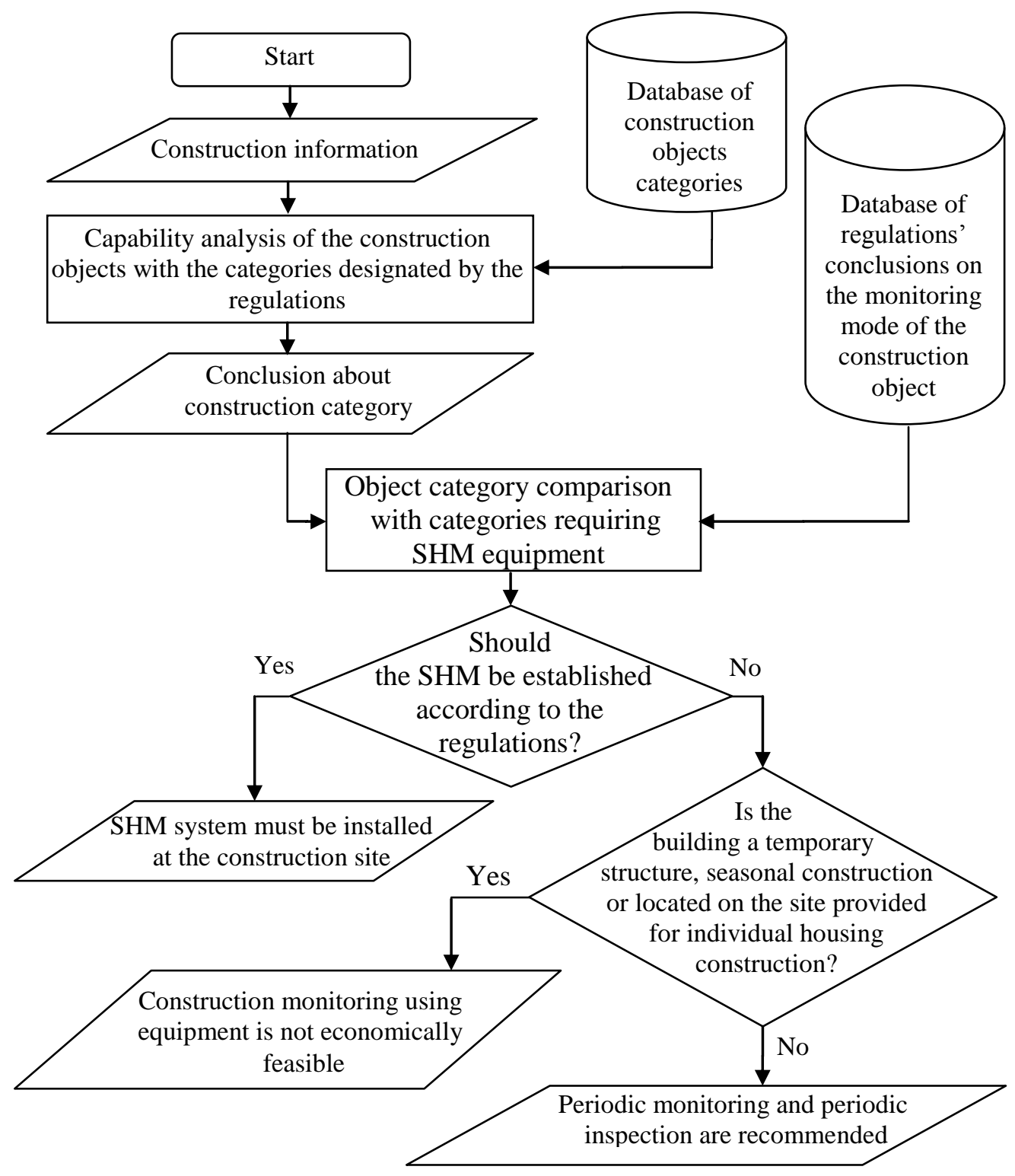

Fig. 1. The algorithm for monitoring mode determination based on information about the construction site.

The optimal implementation environment for the developed information technology are database management programs, in particular, MS Access is a convenient multifunctional platform for developing database management solutions, the main advantages of which are the wide possibilities for data storage and retrieval, the presentation of information in a convenient form and the automation of repetitive tasks.

For effective finite element modeling, it is necessary to use a software package that should meet the following requirements:

- verification - should be able to solve issues using geometrical and physical nonlinearity, and also be able to use a programming language to automate the construction and adjustment of design schemes; 
- able to solve design issues and building and structures calculations;

- can be exported the finite element model to other FEM systems to control the solutions obtained.

The implementation of the information technology was carried out during the on the development of a SHM project (at the operation stage) at The Atomic Energy Pavilion at the VDNKh during construction.

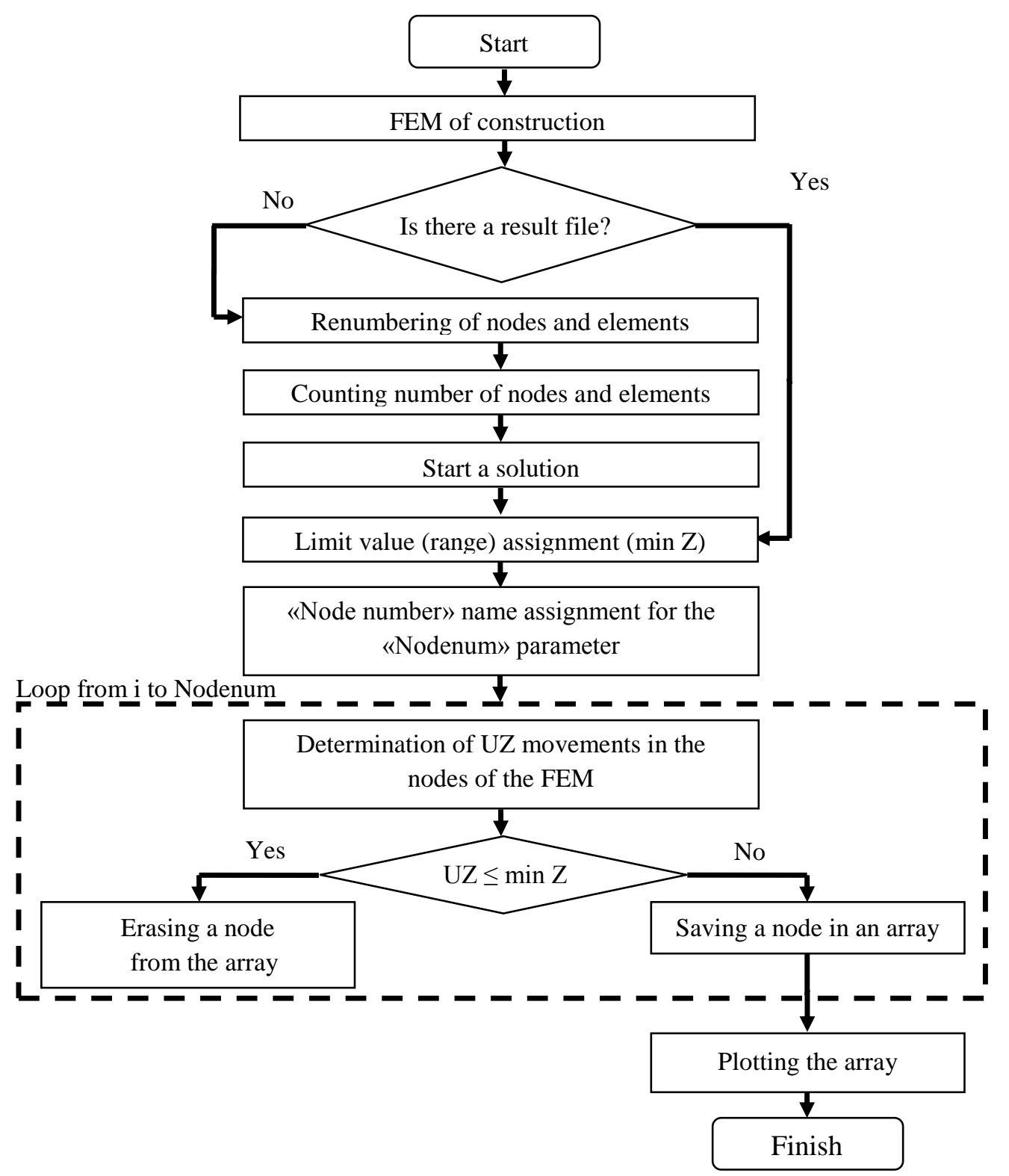

Fig. 2. The algorithm of the macro for the most loaded nodes and elements determination. 


\section{Conclusions}

The key features of the developed information technology allowed the development of the software for effective construction site and engineering survey results data analysis in order to automate the development of SHM projects for typical categories of construction objects.

Due to the growth rate of the "I" (high) responsibility level of construction objects, the relevant objective in the area of this research is the further improvement of automation solutions for the SHM projects development for high-rise buildings and large-span buildings and structures.

\section{References}

1. Safety in emergencies. Structured system for monitoring and control of building / construction engineering equipment. General requirements.

2. Korgin A.V., Emelianov M.V. Mechanization of construction. 9. P. 18-20. (2010)

3. Korgin A.V., Zakharchenko M.A., Ermakov V.A. Monitoring. Science and security. 3. P. 58-63. (2011)

4. Korgin A.V., Shablinskiy G.E., Sergeevtsev E.Yu., Zubkov D.A. Vestnik MGSU. 4. P. 222-228. (2011)

5. Korgin A.V., Zakharchenko M.A. Vestnik MGSU. 11. P.200-205. (2011)

6. Korgin A.V., Ranov I.I., Ermakov V.A., Emelianov M.V., Zeid Kilani L.Z. Industrial and civil engineering. 12. P.13-15. (2012)

7. Korgin A.V., Emelianov M.V., Ermakov V.A., Zeid Kilani L.Z., Krasochkin A.G. Romanets V.A. Vestnik MGSU. 9 P.135-142. (2013)

8. Korgin A.V., Ermakov V.A., Zeid Kilani L.Z., Smirnov V.A., Krasochkin A.G. Romanets V.A. Scientific review. 20. P.191-198. (2015)

9. Suscheev S.P., Samarin V.V., Adamenko I.A., Sotin V.N. Prevention of accidents of buildings and structures: Collection of scientific papers, issue 8. 580 p., P. 15-26. (2009)

10. Shakhraman'yan A.M. [Electronic resourse] URL: http://pamag.ru/pressa/tech-construct (access date 20.01.2019) (in Russ.)

11. Shakhraman'yan A.M. / Modern systems and means of complex safety and fire protection of construction objects. Information collection. M.: GUP "ITC of Moscomarchitecture". 224 p., P. 94-97. (2009)

12. Shakhraman'yan A.M., Kolotovichev Yu.A. Vestnik MGSU. 12. P. 92-105. (2015)

13. Gur'ev V.V., Dorofeev V.M. Monitoring of technical condition of buildings and structures. [Electronic resourse] URL: http://stroyprofile.com/archive/1738 (access date 20.01.2019)

14. Dorofeev V.M., Bulykin I.I., Naz'mov N.V. Industrial and civil engineering. 4. P.28-29. (2006)

15. Gur'ev V.V., Dorofeev V.M. Building materials, equipment, technologies of the XXI century. 7. P. 68-69. . (2006)

16. Volkov O.S., Kletsin V.I. Patent RU No. 2413193 MPK G01M 7/00. Publ. 27.02.2011. Bul. No. 6

17. Methods of monitoring the state of load-bearing structures of buildings and structures. General provisions and requirements. // Non-governmental educational institution "training and consulting center "BASIS". Moscow, 36 p. (2008)

18. Nikolaev S.V., Ostretsov V.M., Gendel'man L.B., Kapustyan N.K., Sukhin V.V. [Electronic resourse] URL: http://www.gpiko.ru/ru/Main/ContentPage/doclad (access date 20.01.2019)

19. Boldurev G.G., Valeev D.N., Zhivaev A.A., Nesterov N.P. Housing construction. 10. P. 38-44. (2010) 
20. Gorpinchenko V.M., Egorov V.I. 10. P. 39-41. (2004)

21. Farrar, C.R. Historical Overview of Structural Health Monitoring. Lecture Notes on Structural Health Monitoring using Statistical Pattern Recognition / C.R. Farrar. - Los Alamos: NM. 150 p. (2001)

22. Joel van Cranenbroeck Geoprofi. 3. P. 6-8. (2007)

23. Norenkov I.P. Fundamentals of computer-aided design: Studies. for universities. 2-e Izd., Rev. and extra - M.: Izd-vo MGTU im. N. E. Bauman. 336 p. (Ser. Computer science at the technical University). (2002) 